\title{
Gaseous Products Evolution Analyses for Catalytic Decomposition of AP by Graphene-Based Additives
}

\author{
Shuwen Chen ${ }^{1}$, Ting An ${ }^{2}$, Yi Gao ${ }^{3}$, Jie-Yao Lyu ${ }^{1}$, De-Yun Tang ${ }^{1}$, Xue-Xue Zhang ${ }^{1}$, \\ Fengqi Zhao ${ }^{2, *}$ and Qi-Long Yan ${ }^{1, * \mathbb{B}}$ \\ 1 Science and Technology on Combustion, Internal Flow and Thermostructure Laboratory, \\ Northwestern Polytechnical University, Xi'an 710072, China; shuwenchen@nwpu.edu.cn (S.C.); \\ jieyaolv@mail.nwpu.edu.cn (J.-Y.L.); tangdy@mail.nwpu.edu.cn (D.-Y.T.); \\ xuexuezhang@mail.nwpu.edu.cn (X.-X.Z.) \\ 2 Science and Technology on Combustion and Explosion Laboratory, Xi'an Modern Chemistry Research \\ Institute, Xi'an 710065, China; anting715@163.com \\ 3 School of Astronautics, Northwestern Polytechnical University, Xi'an 710072, China; gy0704@163.com \\ * Correspondence: zhaofqi@163.com (F.Z.); qilongyan@nwpu.edu.cn (Q.-L.Y.)
}

Received: 13 March 2019; Accepted: 17 May 2019; Published: 24 May 2019

\begin{abstract}
A quantitative evaluation method has been developed to study the effects of nanoadditives on thermal decomposition mechanisms of energetic compounds using the conventional thermogravimetry coupled with mass spectrometry (TG/MS) technique. The decomposition of ammonium perchlorate (AP) under the effect of several energetic catalysts has been investigated as a demonstration. In particular, these catalysts are transition metal $\left(\mathrm{Cu}^{2+}, \mathrm{Co}^{2+}\right.$ and $\left.\mathrm{Ni}^{2+}\right)$ complexes of triaminoguanidine (TAG), using graphene oxide (GO) as dopant. They have been well-compared in terms of their catalytic effects on the concentration of the released gaseous products of AP. These detailed quantitative analyses of the gaseous products of AP provide a proof that the proton transfer between $\cdot \mathrm{O}$ and $\mathrm{O}_{2}$ determines the catalytic decomposition pathways, which largely depend on the type of reactive centers of the catalysts. This quantitative method could be applied to evaluate the catalytic effects of any other additives on the thermal decomposition of various energetic compounds.
\end{abstract}

Keywords: thermolysis; energetic materials; GO-based catalysts; quantitative analyses; decomposition mechanisms

\section{Introduction}

Energetic materials (EMs) are widely used as propellants, explosives, and pyrotechnics. The conventional EMs, such as 1,3,5-trinitro-1,3,5-triazinane (RDX), 1,3,5,7-tetranitro-1,3,5,7-tetrazocane (HMX), and ammonium perchlorate (AP), are still playing dominant roles in the formulations. The nano-sized additives are usually used to improve their performances and more innovative additives have been designed and used during past decades [1-3]. The decomposition and combustion of EMs are the key parameters that have to be investigated before their applications, which are strongly connected with their compatibility, safety, and performance. The decomposition has been found to be the initial stage of combustion, and it should be well-evaluated at laboratory scale. AP is a well-known oxidizer in solid composite propellants. In order to get the burning behavior of propellants, researchers usually focus on their thermal property first $[4,5]$. The thermal behavior of AP has been widely studied during the past several decades [6,7]. Nanoadditives have high concentrations of dislocations and large surface areas, and therefore they normally show significant catalytic effects on the decomposition of AP [8-11]. However, the nanoadditives used today in formulations are mostly inert metal oxides or metal oxide composites. To some extent, they may reduce the energy content of the propellants. 
In order to overcome the limitations mentioned above, one has to develop energetic metal complexes or metal organic frameworks (MOFs) with great thermal stability and compatibility as energetic catalysts. It has been recently shown that graphene oxide (GO) doped transition metal complexes are promising energetic catalysts $[12,13]$. It has been reported that the intrinsic exothermicity of GO (1600 J g $\left.{ }^{-1}\right)$ is comparable to several hazardous chemicals and explosives [14]. In addition, GO could be considered as a stabilizing agent [15]. In our recent study, GO-doped transition metal (nickel, cobalt and copper) complexes of triaminoguanidine (TAG) were prepared, and their effects on the thermal properties and decomposition mechanisms of RDX studied [16]. These materials could not only catalyze the decomposition of RDX, but also improve the thermal stability of RDX due to their enhanced thermal conductivity. The decomposition behavior of GO complexes modified AP have been briefly studied based on conventional thermogravimetry coupled with mass spectrometry (DSC/TG) analysis [17]. The results showed that the hybrid catalysts can enhance the initial decomposition temperature and change the thermolysis mechanism by introducing different types of metal ions. But the detailed effect of nanoadditives, especially for GO-based energetic catalysts, on thermolysis products and reaction pathways of AP are not well investigated [18]. According to the literature, two mechanisms have been proposed for the thermal decomposition of AP: (a) electron transfer mechanism [19] and (b) proton transfer mechanism [20], depending on the temperature. A large amount of data has shown that the GO-TAG based catalysts have significant effects on heat releases and thermal stability of EMs, but the inherent chemical mechanisms are still not well-known.

Therefore, this paper intends to present a comprehensive quantitative analysis to clarify how nanoadditives affect the decomposition mechanisms of EMs. The catalytic effects of GO-based energetic additives on thermal decomposition chemical pathways and gaseous products of AP have been investigated as a typical demonstration. It is a novel method to get the catalyst mechanism by measuring the amount of gaseous decomposition products. Thermal analysis techniques including thermogravimetry coupled with mass spectrometry (TG/MS) were employed to evaluate the decomposition mechanisms [21-23]. This technique was used to evaluate the bond breaking and gaseous products formation during thermal decomposition of EMs. Thus, this work aims at studying the thermal decomposition of AP, in presence of various GO-TAG based energetic catalysts, on the basis of TG/MS technique.

\section{Experimental Procedure}

\subsection{Sample Preparation}

G-T-M and TAG-M composites were synthesized followed by the method reported in the previously published paper ([16], the preparation was summarized in the supporting materials). In order to get AP contained complex, a saturated solution of AP containing $160 \mathrm{mg}$ of AP and $20 \mathrm{~mL}$ of acetone was prepared first. Then $40 \mathrm{mg}$ TAG-M or G-T-M was added to this solution (M means Nickel, Cobalt or Copper ion), and stirred for $3 \mathrm{~h}$ at room temperature. The final G-T-M/AP and TAG-M/AP complexes were obtained after freeze drying. Warning - the solvent-free TAG-Cu complex would undergo self-ignition and fast deflagration to detonation transition reaction easily in the presence of oxygen.

G-T-M indicates GO-doped transition metals complexes of TAG. TAG-M is transition metals modified TAG. G-T-M/AP and TAG-M/AP correspond to G-T-M and TAG-M doping AP, respectively. The components of G-T-M/AP and TAG-M/AP have been summarized in Table 1.

Table 1. The compositions of ammonium perchlorate (AP)-based mixtures (in weight percent).

\begin{tabular}{ccccc}
\hline & AP & GO & TAG & Metal \\
\hline G-T-Co/AP & $80 \%$ & $0.4 \%$ & $5.0 \%$ & $14.6 \%$ Cobalt \\
G-T-Cu $/$ AP & $80 \%$ & $0.4 \%$ & $5.7 \%$ & $13.9 \%$ Copper \\
G-T-Ni/AP & $80 \%$ & $0.5 \%$ & $6.6 \%$ & $12.9 \%$ Nickel \\
TAG-Co/AP & $80 \%$ & - & $6.3 \%$ & $13.7 \%$ Cobalt \\
TAG-Ni/AP & $80 \%$ & - & $7.1 \%$ & $12.9 \%$ Nickel \\
\hline
\end{tabular}




\subsection{Experimental Techniques}

The gaseous products from thermal decomposition of AP and AP-based mixtures using TAG-M and G-T-M as energetic nanoadditives were detected using the TG-DSC/MS technique. This experiment was realized on a simultaneous thermoanalyzer STA 449 F3 coupled with a quadrupole mass spectrometer QMS 403 C Aëolos (Netzsch Group, Selb, Germany). An alumina pan with a pin-hole cover was used as a sample pan). The sample masses for these measurements were about $3 \mathrm{mg}$, with a heating rate of $10^{\circ} \mathrm{C} / \mathrm{min}$ in a temperature range of $40-500^{\circ} \mathrm{C}$, using an argon atmosphere (gas flow: $50 \mathrm{~mL} / \mathrm{min}$ ).

\section{Results and Discussion}

\subsection{Possible Catalytic Decomposition Pathways of AP}

According to the literature [24-26], there are two possible decomposition processes for AP; the low and high temperature stages. Since AP contains plenty of nuclei with tiny pores [27], they are likely to provide highly active sites on their surface at the low temperature decomposition stage, while the high-temperature decomposition stage takes place at the surfaces of the nanocrystals, and involves adsorption and desorption of ammonia as well as perchloric acid. The decomposition of AP generally follows two steps [28,29]; a solid-gas multiphase reaction of the first decomposition step at $300-330^{\circ} \mathrm{C}$, and a gas phase reaction of the second decomposition step at $450-480{ }^{\circ} \mathrm{C}$. The possible decomposition reactions and transformations are as follows [27]:

$$
\begin{gathered}
\mathrm{NH}_{4} \mathrm{ClO}_{4} \rightarrow \mathrm{NH}_{3}+\mathrm{HClO}_{4} \\
\mathrm{HClO}_{4} \rightarrow 2 \mathrm{O}_{2}+\mathrm{HCl} \\
\mathrm{O}_{2} \rightarrow \mathrm{O}_{2}^{-} \\
4 \mathrm{NH}_{4}{ }^{+}+\mathrm{O}_{2}^{-} \rightarrow 2 \mathrm{H}_{2} \mathrm{O}+4 \mathrm{NH}_{3} \\
7 \mathrm{ClO}_{4}{ }^{-} \rightarrow 2 \mathrm{ClO}_{3}+\mathrm{ClO}_{2}+2 \mathrm{ClO}+9 \mathrm{O}_{2}+\mathrm{Cl}_{2} \\
4 \mathrm{NH}_{3}+5 \mathrm{O}_{2} \rightarrow \mathrm{N}_{2} \mathrm{O}+\mathrm{NO}+\mathrm{NO}_{2}+6 \mathrm{H}_{2} \mathrm{O}
\end{gathered}
$$

As mentioned above, the TG/MS technique has been used to detect the products of thermal decomposition of AP and TAG-based catalysts coated AP. The major gas products have been found to be $\mathrm{O}_{2}, \mathrm{NO}, \mathrm{NH}_{3}, \mathrm{H}_{2} \mathrm{O}, \cdot \mathrm{O}$, which would be used to clarify the possible catalytic decomposition mechanisms.

As shown in Figure 1a, there are two obvious gas evolution peaks at around $308-323{ }^{\circ} \mathrm{C}$ and $438-445{ }^{\circ} \mathrm{C}$ for pure $\mathrm{AP}$, which are attributed to the low-temperature decomposition and high-temperature decomposition, respectively. Compared with pure AP, G-T-Cu $/ 2 \mathrm{AP}$ shows only one gas release peak between $328{ }^{\circ} \mathrm{C}$ and $342{ }^{\circ} \mathrm{C}$. The G-T-Cu $-\mathrm{Cu}_{2} / \mathrm{AP}$ decomposes with a single but wide releasing peak, so G-T-Cu $\mathrm{Cu}_{2}$ has a catalyst effect on AP decomposition. In the presence of TAG-Ni, the decomposition peak of the first step has the same temperature range as that of pure $\mathrm{AP}$, and the second peak temperature has decreased by about $40^{\circ} \mathrm{C}$. The addition of TAG-Ni has a larger effect on the releasing amount of $\mathrm{NO}$ and $\cdot \mathrm{O}$. For the mixture of G-T-Ni/AP, as shown in Figure 1d, there is only one decomposition peak similar to that of G-T-Cu $/ \mathrm{AP}$, but with a higher peak temperature in the range of $364-383^{\circ} \mathrm{C}$. The results suggest that G-T-Ni can improve the thermal stability of AP compared with G-T- $-\mathrm{Cu}_{2}$.

A sharp decomposition peak can be observed for TAG-Co/AP with the range of $297-301{ }^{\circ} \mathrm{C}$, so the presence of TAG-Co has a large catalytic effect on AP decomposition by decreasing the amount of released gases and decomposition temperature. All the gas products are releasing at almost the same temperature. Regarding G-T-Co/AP, the decomposition peak is smoother and the peak temperature increases by $10-20^{\circ} \mathrm{C}$ with the addition of GO. It has been reported that G-T-Co can slightly increase the thermal stability of AP [17]. The results indicate that TAG-M complexes in the presence of GO can enhance thermal stability for $\mathrm{AP}$, resulting in slower reaction rates at a higher temperature range. 

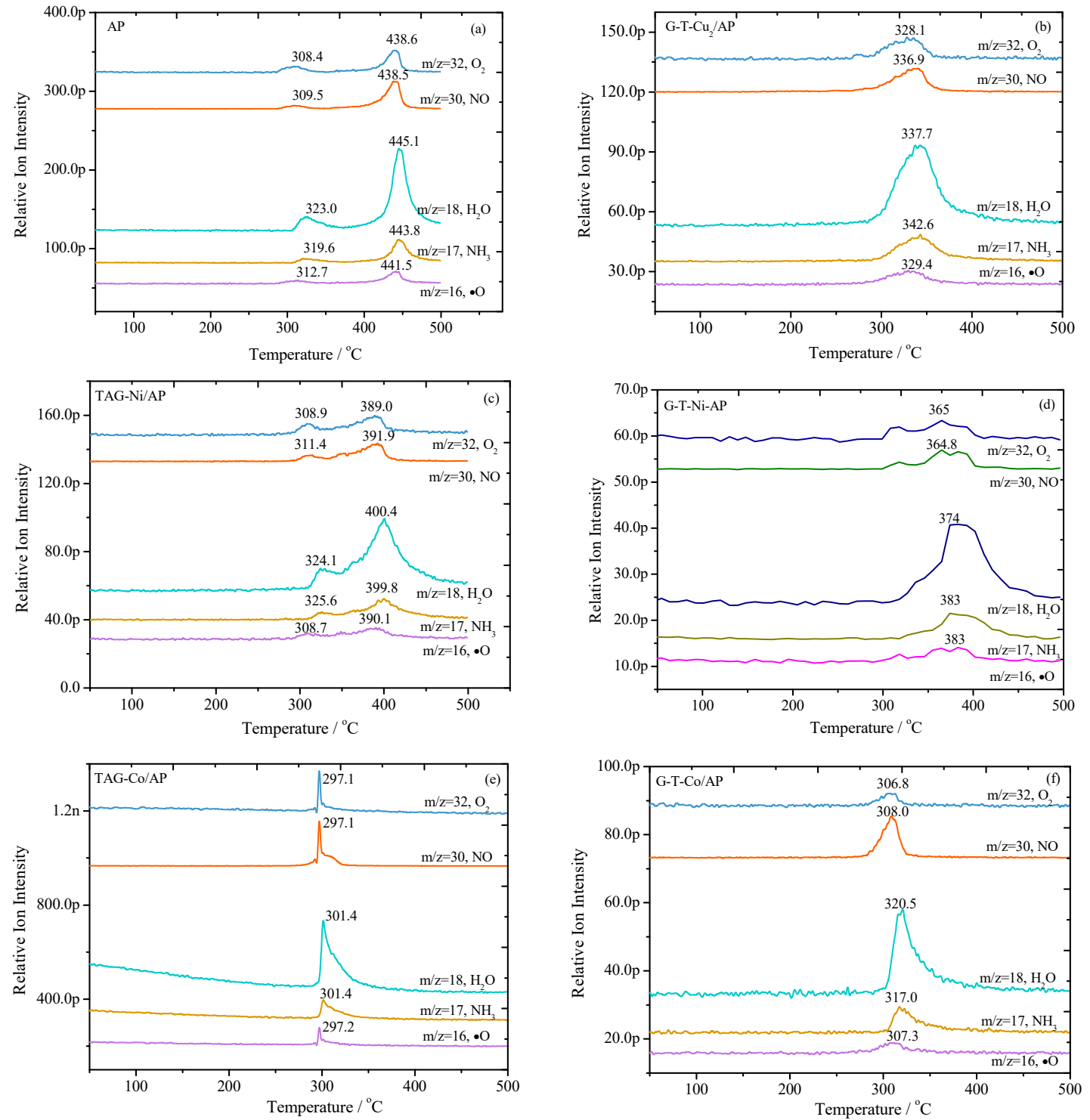

Figure 1. Temperature dependency of the ion flows from non-isothermal decomposition for pure $\mathrm{AP}$ and coated AP under a heating rate of $10^{\circ} \mathrm{C} \mathrm{min}^{-1}$ using thermogravimetry coupled with mass spectrometry (TG/MS) technique: (a) pristine AP; (b) G-T-Cu2/AP; (c) TAG-Ni/AP; (d) G-T-Ni/AP; (e) TAG-Co/AP; (f) G-T-Co/AP; TAG-triaminoguanidine.

\subsection{The Dependence of Gases' Evolution Processes on Temperature for Catalytic Decomposition of AP}

The curves in Figure 1 were derived and summarized as a function of gaseous product types, as shown in Figure 2.

For the decomposition of pure AP (Figure 2f), the sequence of its gas releasing process is as follows: $\mathrm{NO}, \cdot \mathrm{O}, \mathrm{O}_{2}, \mathrm{NH}_{3}$ and $\mathrm{H}_{2} \mathrm{O}$. The releasing rate of $\mathrm{NO}$ and $\cdot \mathrm{O}$ increases rapidly at around $300{ }^{\circ} \mathrm{C}$, and then slows down when the temperature reaches $350^{\circ} \mathrm{C}$. In the meantime, the other three kinds of gases start to release. The releasing rates of all the gaseous products reach their maximum values at the temperature of $420{ }^{\circ} \mathrm{C}$, and start to decrease when the temperature is over $450{ }^{\circ} \mathrm{C}$. The two releasing stages correspond to two decomposition peaks in Figure 1a. Compared with pure AP, the addition of TAG-M complexes could affect the gaseous releasing processes due to the change of chemical reaction pathways, which will be discussed in more detail in a later section.

There is only a trace amount of $\cdot \mathrm{O}(\mathrm{m} / \mathrm{z}=16)$ radical being formed for all involved samples. The release of $\cdot \mathrm{O}$ is even earlier than that of pure AP in the presence of G-T-Co, G-T-Cu $\mathrm{Cu}_{2}$ and TAG-Co 
complexes, but TAG-Ni and G-T-Ni complexes postponed the reactions that would release $\cdot \mathrm{O}$. The mass loss of AP in these cases should be largely caused by the transformation of $\mathrm{O}_{2} \rightarrow \mathrm{O}_{2}^{-}$that forms -O radical, which has been demonstrated by the curve of $m / z=16$ in Figure 1. Five kinds of TAG-based complexes have similar catalytic effects on reaction temperature, which lead to the formation of $\mathrm{NH}_{3}$ $(m / z=17)$ and $\mathrm{H}_{2} \mathrm{O}(\mathrm{m} / \mathrm{z}=18)$, where the releasing rate of gas is increased. In comparison, G-T-Ni postpones the temperature at which $\mathrm{NO}(\mathrm{m} / \mathrm{z}=30)$ starts to release. It also improves the thermal stability of AP, whereas the other four types of G-T-M complexes decrease the initial gas releasing temperature of AP. The initial decomposition temperature of AP is decreased, and the reaction rate is increased in formation of $\mathrm{O}_{2}(m / z=32)$, by using TAG-M complexes as additives.
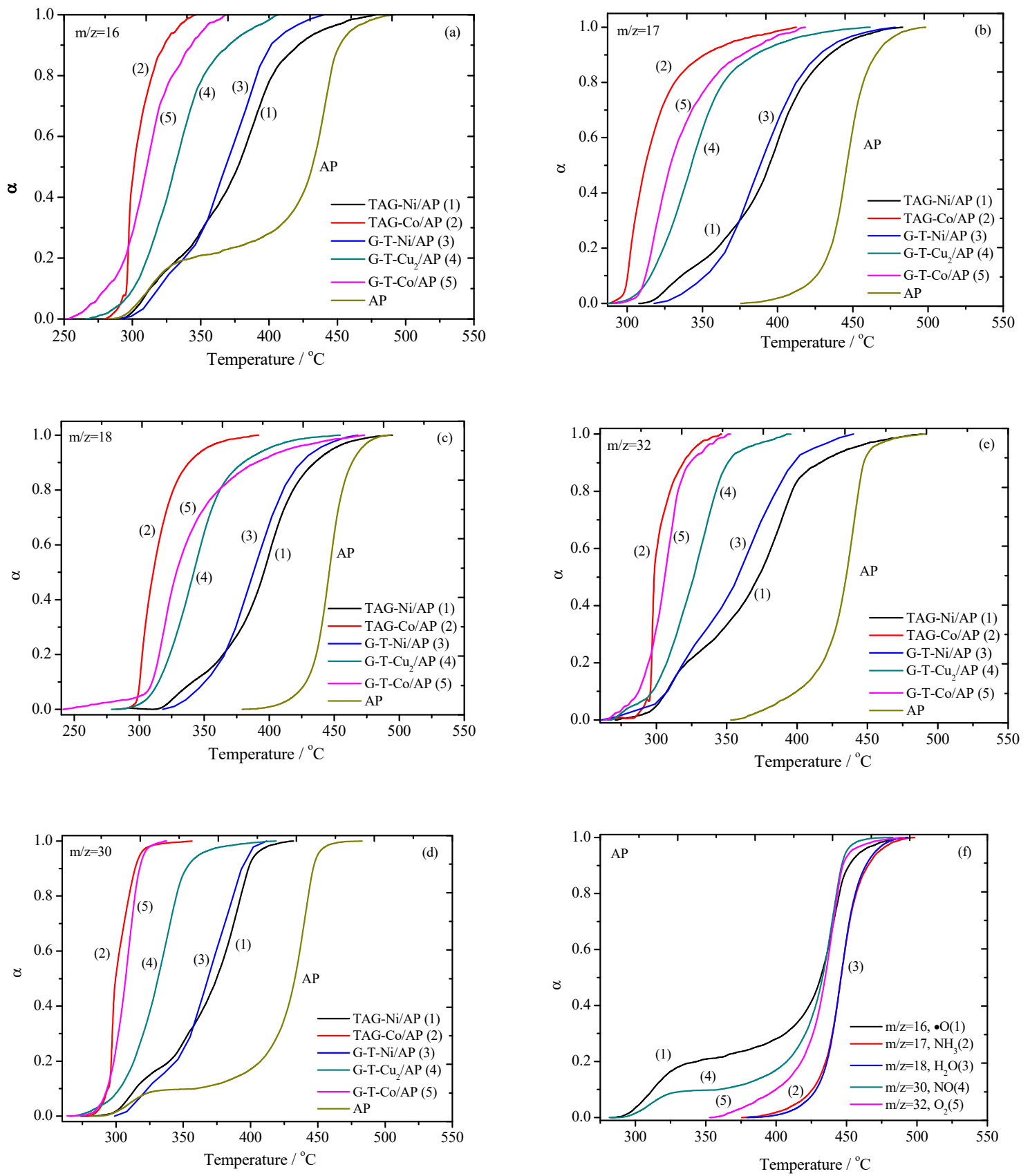

Figure 2. The dependence of accumulation ( $\alpha$ is conversion rate) of the typical gaseous products on the temperature for AP-based mixtures: (a) $m / z=16, \cdot \mathrm{O} ;$ (b) $m / z=17, \mathrm{NH}_{3} ;$ (c) $m / z=18, \mathrm{H}_{2} \mathrm{O}$; (d) $m / z=\mathrm{O}_{2}$; (e) $m / z=30, \mathrm{NO}$ (f) summary of products evolution processes of pristine AP. 
In the presence of TAG-Ni, all the gas release processes occur in two steps, which is similar to the case of pure AP. G-T-Ni/AP has a lower initial temperature for releasing $\mathrm{O}_{2}$ and $\cdot \mathrm{O}$ than that of TAG-Ni/AP. However, the initial releasing temperature for $\mathrm{NO}, \mathrm{NH}_{3}$ and $\mathrm{H}_{2} \mathrm{O}$ of G-T-Ni/AP is higher than that of TAG-Ni/AP. If comparing G-T-Co/AP with TAG-Co/AP, the initial temperatures for the production of $\mathrm{NO}, \mathrm{O}_{2}, \cdot \mathrm{O}$ and $\mathrm{H}_{2} \mathrm{O}$ are much lower, where extra $\mathrm{NH}_{3}$ was generated. The gas releasing rate of TAG-Co/AP is also higher than that of G-T-Co/AP throughout their decomposition. The G-T-Cu $\mathrm{Cu}_{2}$ has a significant catalytic effect on AP decomposition so that the stabilization of GO is excluded. It is clear that the initial temperature of $\mathrm{G}-\mathrm{T}-\mathrm{Cu}_{2}$ has been decreased in comparison to pure AP. In summary, the addition of TAG-M complexes to AP may lead to significant changes in the chemical decomposition pathways.

\subsection{Quantitative Analyses of Gaseous Products' Changes of AP in Presence of These Nanocatalysts}

To study the catalytic effect of TAG-based complexes on the decomposition mechanisms of AP, the ion flow curves (Figure 1) have been integrated and analyzed. In order to make a quantitative comparison, the characteristic parameters of these curves are calculated and summarized in Table 2.

Table 2. A summary of TG/MS parameters of AP coated by different GO (graphene-oxide)-based catalysts.

\begin{tabular}{|c|c|c|c|c|c|}
\hline \multicolumn{6}{|c|}{$m / z=16, \cdot \mathrm{O}$} \\
\hline & $T_{\mathrm{o}}$ & $T_{\mathrm{e}}$ & $\Delta T$ & $\mathbf{n}$ & $\mathbf{n}_{\mathrm{m}}$ \\
\hline TAG-Ni/AP & 289.9 & 478.0 & 188.1 & $4.541 \times 10^{-10}$ & $9.69 \%$ \\
\hline TAG-Co/AP & 279.4 & 346.7 & 67.3 & $5.803 \times 10^{-10}$ & $5.81 \%$ \\
\hline G-T-Ni/AP & 289 & 440 & 151 & $1.969 \times 10^{-10}$ & $8.92 \%$ \\
\hline G-T-Cu $\mathrm{u}_{2} / \mathrm{AP}$ & 266.2 & 406.7 & 140.5 & $3.653 \times 10^{-10}$ & $8.93 \%$ \\
\hline G-T-Co/AP & 251.5 & 369.2 & 117.7 & $1.330 \times 10^{-10}$ & $7.79 \%$ \\
\hline $\mathrm{AP}$ & 282.7 & 491.2 & 208.5 & $5.734 \times 10^{-10}$ & $9.87 \%$ \\
\hline \multicolumn{6}{|c|}{$m / z=17, \mathrm{NH}_{3}$} \\
\hline TAG-Ni/AP & 307.8 & 483.1 & 175.3 & $7.052 \times 10^{-10}$ & $15.04 \%$ \\
\hline TAG-Co/AP & 287.6 & 412.5 & 124.9 & $16.89 \times 10^{-10}$ & $16.90 \%$ \\
\hline G-T-Ni/AP & 318 & 478 & 160 & $3.607 \times 10^{-10}$ & $16.34 \%$ \\
\hline $\mathrm{G}-\mathrm{T}-\mathrm{Cu}_{2} / \mathrm{AP}$ & 287.2 & 461.5 & 174.3 & $6.389 \times 10^{-10}$ & $15.62 \%$ \\
\hline G-T-Co/AP & 291.2 & 418.4 & 127.2 & $2.595 \times 10^{-10}$ & $15.19 \%$ \\
\hline $\mathrm{AP}$ & 375.6 & 498.4 & 122.8 & $7.706 \times 10^{-10}$ & $13.27 \%$ \\
\hline \multicolumn{6}{|c|}{$m / z=18, \mathrm{H}_{2} \mathrm{O}$} \\
\hline TAG-Ni/AP & 292.5 & 494.6 & 202.1 & $22.849 \times 10^{-10}$ & $48.73 \%$ \\
\hline TAG-Co/AP & 282.3 & 391.8 & 109.5 & $53.426 \times 10^{-10}$ & $53.47 \%$ \\
\hline G-T-Ni/AP & 318 & 468 & 150 & $11.052 \times 10^{-10}$ & $50.07 \%$ \\
\hline $\mathrm{G}-\mathrm{T}-\mathrm{Cu}_{2} / \mathrm{AP}$ & 278.7 & 454.5 & 175.8 & $20.80 \times 10^{-10}$ & $50.85 \%$ \\
\hline G-T-Co/AP & 241.3 & 473.3 & 232 & $9.531 \times 10^{-10}$ & $55.79 \%$ \\
\hline $\mathrm{AP}$ & 379.2 & 493.5 & 114.3 & $26.328 \times 10^{-10}$ & $45.34 \%$ \\
\hline \multicolumn{6}{|c|}{$m / z=30, \mathrm{NO}$} \\
\hline TAG-Ni/AP & 273.7 & 431.9 & 158.2 & $5.153 \times 10^{-10}$ & $10.99 \%$ \\
\hline TAG-Co/AP & 277.7 & 356.5 & 78.8 & $14.65 \times 10^{-10}$ & $14.66 \%$ \\
\hline G-T-Ni/AP & 299 & 412 & 113 & $2.138 \times 10^{-10}$ & $9.69 \%$ \\
\hline $\mathrm{G}-\mathrm{T}-\mathrm{Cu}_{2} / \mathrm{AP}$ & 265.3 & 419.0 & 153.7 & $5.010 \times 10^{-10}$ & $12.25 \%$ \\
\hline G-T-Co/AP & 263.7 & 337.6 & 73.9 & $2.552 \times 10^{-10}$ & $14.94 \%$ \\
\hline $\mathrm{AP}$ & 281.5 & 482.8 & 201.3 & $10.604 \times 10^{-10}$ & $18.26 \%$ \\
\hline \multicolumn{6}{|c|}{$m / z=32, \mathrm{O}_{2}$} \\
\hline TAG-Ni/AP & 270.8 & 488.9 & 218.1 & $7.291 \times 10^{-10}$ & $15.55 \%$ \\
\hline $\mathrm{TAG}-\mathrm{Co} / \mathrm{AP}$ & 266.4 & 346.3 & 79.9 & $9.146 \times 10^{-10}$ & $9.15 \%$ \\
\hline G-T-Ni/AP & 261 & 440 & 179 & $3.305 \times 10^{-10}$ & $14.97 \%$ \\
\hline $\mathrm{G}-\mathrm{T}-\mathrm{Cu}_{2} / \mathrm{AP}$ & 265.0 & 395.5 & 130.5 & $5.055 \times 10^{-10}$ & $12.36 \%$ \\
\hline G-T-Co/AP & 262.9 & 352.6 & 89.7 & $1.075 \times 10^{-10}$ & $6.29 \%$ \\
\hline $\mathrm{AP}$ & 352.8 & 491.4 & 138.6 & $7.701 \times 10^{-10}$ & $13.26 \%$ \\
\hline
\end{tabular}

Notes: $T_{\mathrm{o}}$, onset temperature of decomposition, in ${ }^{\circ} \mathrm{C} ; T_{\mathrm{e}}$, the end temperature of decomposition, in ${ }^{\circ} \mathrm{C} ; \Delta T, T_{\mathrm{e}}-T_{\mathrm{o}}$, in ${ }^{\circ} \mathrm{C} ; \mathrm{n}$, the amount of each released gas; $\mathrm{n}_{\mathrm{m}}$, proportion of each product in total gaseous products. 
Many investigations have shown that AP decomposition proceeds via the electron transfer from the cation $\mathrm{NH}_{4}{ }^{+}$to anion $\mathrm{ClO}_{4}{ }^{-}$, and the catalytic processes with nanocrystalline additives involve the electron transfer between AP and nanoadditives. Boldyrev [28] concluded that the AP decomposition process is followed by a proton transfer from the cation $\mathrm{NH}_{4}{ }^{+}$to anion $\mathrm{ClO}_{4}{ }^{-}$. We may assume that the addition of TAG-M complex has catalytic activity in AP decomposition. The amount of gaseous product is different depending on the type of catalysts. For TAG-M doped by GO, the nanocrystalline of TAG-M grows uniformly on the graphene nanosheets, which can increase the contact surface area between AP with the active electron transfer centers, thus resulting in accelerated thermolysis reaction processes. The GO-doped TAG-M complexes with different metal centers could either postpone or accelerate the initial decomposition of AP. According to the quantitative change of gases by TG-DSC/MS technique, the reaction pathways have been greatly changed by these catalysts, depending on the type of metal ions.

For releasing $\cdot \mathrm{O}$, TAG-Ni and G-T-Ni have little influence on the initial temperature of decomposition, but G-T-Ni/AP can help increase the reaction rate compared with TAG-Ni/AP and AP. The addition of TAG-Co, G-T-Co or G-T-Cu $\mathrm{Cu}_{2}$ increases the initialization temperature and shortens the reaction time. For the reaction to produce $\mathrm{NH}_{3}$, TAG-M complex decreased the initial reaction temperature of $\mathrm{NH}_{3}$ by $57.6-88.4{ }^{\circ} \mathrm{C}$ while increasing the reaction time. For the reaction to produce $\mathrm{NO}, \mathrm{G}-\mathrm{T}-\mathrm{Ni} / \mathrm{AP}$ postpones the initial reaction temperature, while the other nano- complexes decrease the initialization temperature. All of these TAG-M complexes have increased the reaction rate.

TAG-Co has shortened the reaction that produces $\mathrm{H}_{2} \mathrm{O}$, whereas the other four types of complexes have prolonged the reaction time by $53.8 \%$ to $100 \%$. The initial decomposition temperature of AP under the effects of all TAG-M complexes have been decreased by $61{ }^{\circ} \mathrm{C}$ to $138{ }^{\circ} \mathrm{C}$. For the releasing of $\mathrm{O}_{2}$, TAG-Co based complex has shortened the reaction time by $35-40 \%$, but Ni-based and Cu-based composites prolong the reaction time by $29-57 \%$. Cu-based component reduces the initial decomposition time and slightly decreases the reaction time by $5.8 \%$.

The amount of each gas product is quantified by integrating the peak area of ion intensity curves in Figure 1. The percentage of major gaseous products for each TAG-M complex was calculated and summarized in Figure 3. The amount of $\mathrm{H}_{2} \mathrm{O}$ and $\mathrm{NH}_{3}$ was increased with the addition of G-T-Cu , while the amount of the other three kinds of gases was reduced. This suggests that G-T-Cu benefits the reaction of $\mathrm{NH}_{4}{ }^{+}$and $\mathrm{ClO}_{4}{ }^{-}$, but suppresses the reaction of oxygen conversion. For TAG-Ni/AP and G-T-Ni/AP, the reactions of producing $\mathrm{NO}$ and $\cdot \mathrm{O}$ were suppressed, but the reactions producing $\mathrm{H}_{2} \mathrm{O}$, $\mathrm{NH}_{3}$ and $\mathrm{O}_{2}$ were promoted. The amount of change of gas released for G-T-Ni/AP is more significant than that of TAG-Ni/AP. For TAG-Ni/AP, the molar ratio of $\cdot \mathrm{O}$ and $\mathrm{H}_{2} \mathrm{O}$ changed by $-1.8 \%$ and $7.5 \%$, respectively. Additionally, TAG-Ni/AP shows two decomposition peaks the same as that of pure AP. The TAG-Co based additives show a similar catalyst effect to that of TAG-Cu $\mathrm{u}_{2}$ complex. The reaction of $\mathrm{O}$ is very sensitive to TAG-Co, which reduces the gas amount by $40 \%$. The decomposition curve of TAG-Co/AP is the sharpest and its reaction time is the shortest. G-T-Co/AP shows the greatest influence on the reaction of producing $\mathrm{O}_{2}$, with a decrease in amount of gas by $52 \%$.

The addition of TAG-M complex has an obvious catalytic effect on the whole decomposition efficiency of $\mathrm{AP}$, where an increase of gas production of $\mathrm{H}_{2} \mathrm{O}$ and $\mathrm{NH}_{3}$ could be found. For the molar ratio of $\cdot \mathrm{O}, \mathrm{TAG}-\mathrm{Ni} / \mathrm{AP}$ presents the lowest reduction rate of gas production at $1.8 \%$, compared to $41.1 \%$ for that of TAG-Co/AP. The amount of $\mathrm{O}_{2}$ generation was reduced for TAG-Co/AP, G-T-Co/AP, and G-T-Cu $/$ AP, while it increased in TAG-Ni/AP and G-T-Ni/AP. Co-based complex shows an obvious reduction in $\mathrm{O}_{2}$ product, among which G-T-Co/AP presents a reduction rate as high as $52.5 \%$. The producing of $\mathrm{NO}$ is the most sensitive to G-T-Ni, with a reduction rate of $46.9 \%$. 


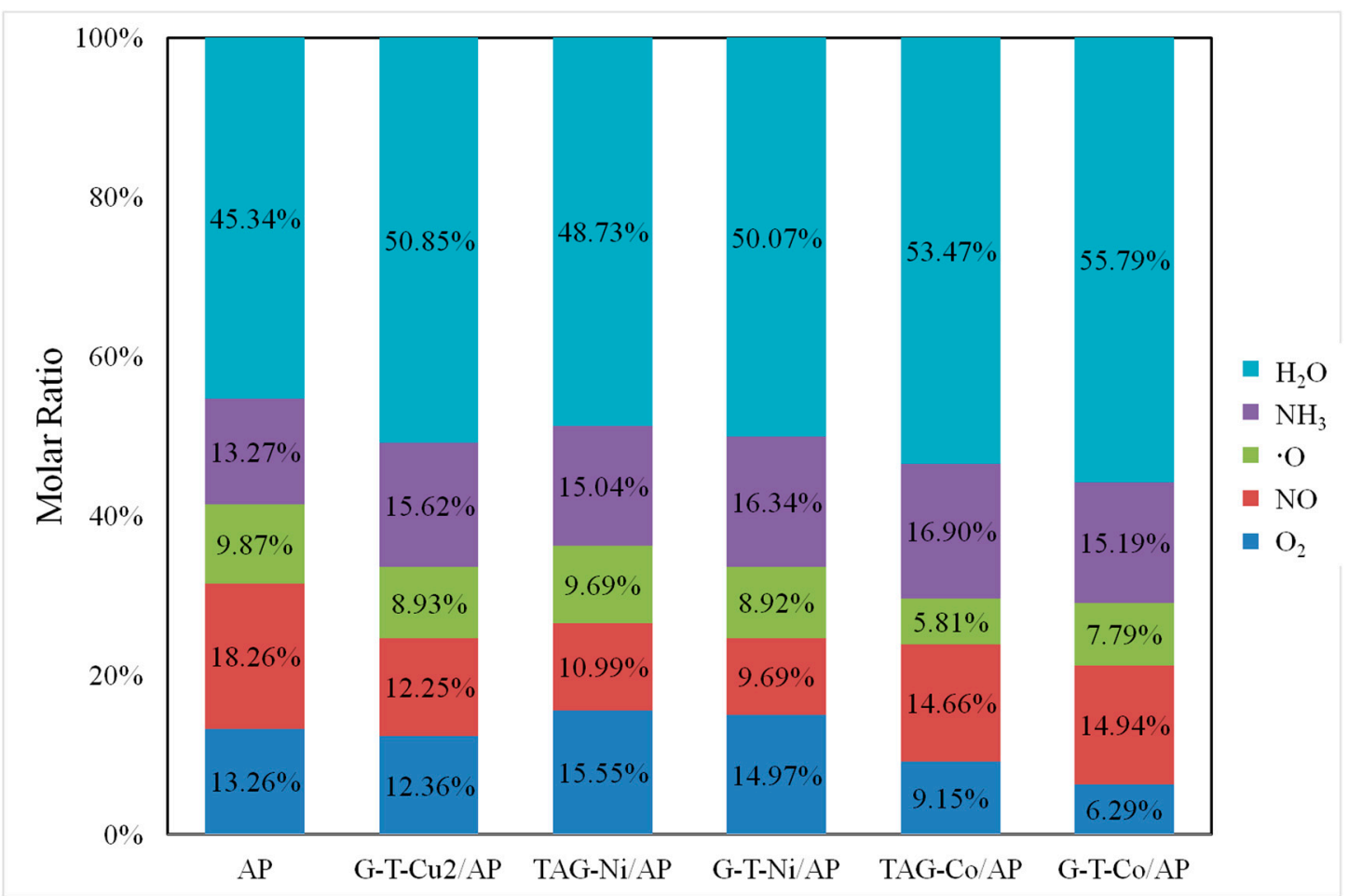

Figure 3. Comparison of molar ratio of gas products decomposed by AP coated with different TAG-M based catalysts.

Figure 4 shows that there is a pair of ions $\left(\mathrm{NH}_{4}{ }^{+}\right.$and $\left.\mathrm{ClO}_{4}{ }^{-}\right)$in $\mathrm{NH}_{4} \mathrm{ClO}_{4}$ crystal lattice. The proton transfers from $\mathrm{NH}_{4}{ }^{+}$to $\mathrm{ClO}_{4}{ }^{-}$, which leads to reaction $b$ and the formation of $\mathrm{NH}_{3}$ and $\mathrm{HClO}_{4}$. Moreover, the graphene could be combined with metal oxides to improve the catalytic activity. For

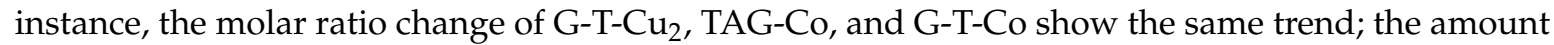
of $\mathrm{H}_{2} \mathrm{O}$ and $\mathrm{NH}_{3}$ is increasing, while the amount of $\cdot \mathrm{O}, \mathrm{NO}$ and $\mathrm{O}_{2}$ is decreasing. According to the amount of change, we can postulate that reactions $a, f$, and $e$ were promoted (Figure 4 ).

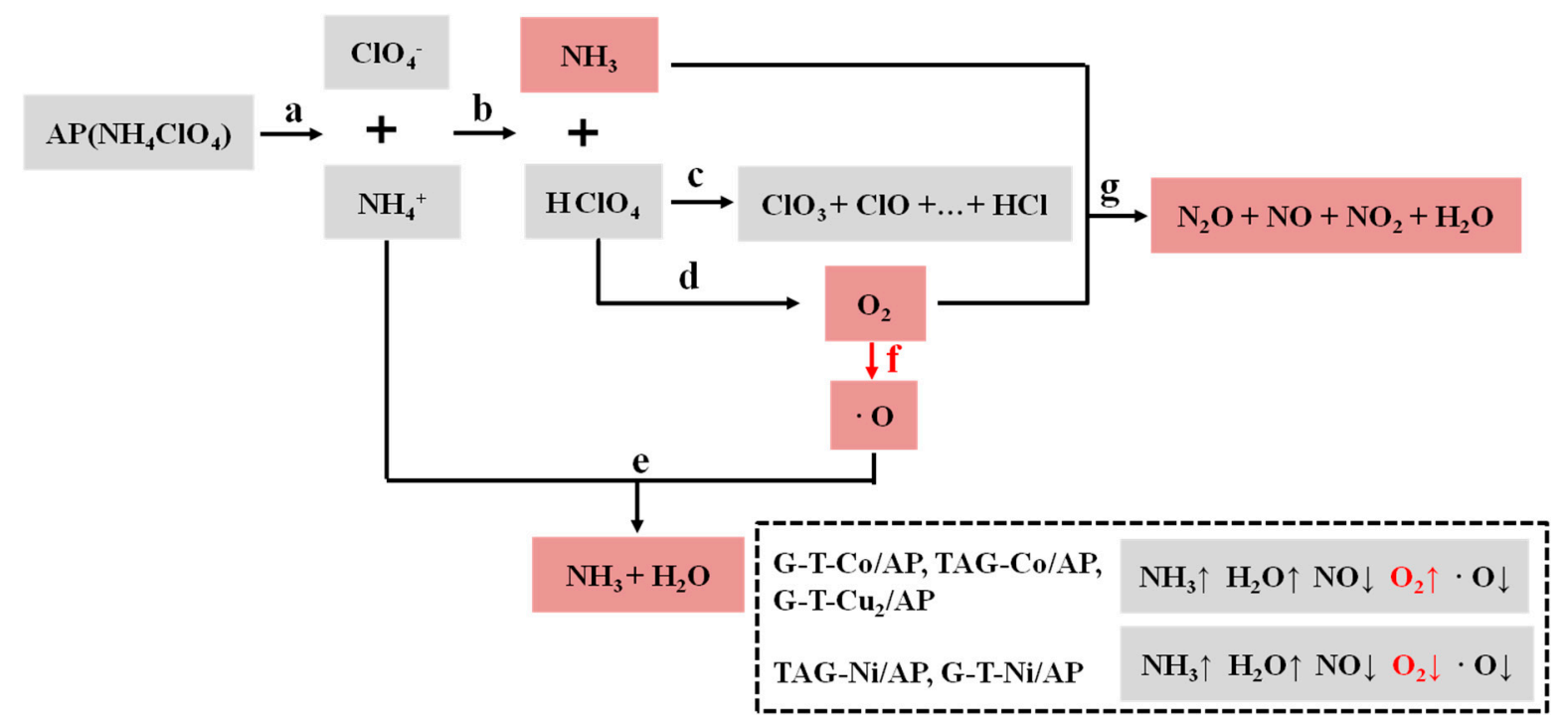

Figure 4. Thermal decomposition mechanisms of AP under the catalytic effects of TAG-M complexes (arrow up means increase and arrow down means decrease). 
For TAG-Co catalyst dispersed in AP, the amount of $\mathrm{O}$ has the minimum value, where one sharp decomposition peak was observed from the ion intensity curve. In the case of G-T-Co/AP, the amount of $\mathrm{O}_{2}$ shows the maximum reduction, while graphene shows additional promotion to reaction $f$. In contrast, TAG-Ni catalyst promotes reaction $d$, but suppresses reaction $g$, while the amount of $\cdot \mathrm{O}$ slightly decreases compared with that of pure AP. G-T-Ni shows catalytic effect on reaction $d$, but suppresses reactions $f$ and $g$.

All TAG-M catalysts could promote the reactions of AP decomposition by increasing the amount of gas products. In addition G-T-Co, TAG-Co, and G-T- $\mathrm{Cu}_{2}$ have stronger catalytic effects than nickel-based compounds, as they could make two-step gas releasing into one step. This conclusion is consistent with the thermal results from our previous research [17], which claimed that all TAG-M based composites could catalyze the first decomposition process of AP, and Co-based and Cu-based materials have stronger catalytic effects.

\section{Conclusions}

TG/MS was used to quantitatively study the effects of additives on decomposition mechanisms of energetic compounds, where catalytic decomposition of AP by GO-based catalysts has been selected as a typical example. It has been demonstrated that the detailed quantitative analyses of the gaseous products of AP would show the inherent mechanism changes under the effects of various additives. This method could be applied to analyze the decomposition mechanisms of any other energetic compounds.

The findings further support the literature on the catalytic decomposition kinetics of AP. The GO-based catalysts show improved catalytic efficiency due to their capability in increasing the conversion rates of $\mathrm{NH}_{3}$ and $\mathrm{H}_{2} \mathrm{O}$. This can be explained by more $\mathrm{O}$ elements being transferred to react with $\mathrm{NH}_{4}{ }^{+}$, which enhances the initial decomposition heat, resulting in the combination of two decomposition peaks. The amount of $\mathrm{O}_{2}$ decreases under the effect of Ni-based complexes, which promote the reaction in producing $\cdot \mathrm{O}$. In particular, new findings suggest that TAG-Ni and G-T-Ni materials have higher stabilization effects on AP than the others. The Co-based and Cu-based composites could increase the release of $\mathrm{O}_{2}$, so they have better catalytic effect on AP decomposition. The improved reactions between $\cdot \mathrm{O}$ and the other radicals mean a better catalytic effect on the decomposition of AP.

Supplementary Materials: The following are available online at http://www.mdpi.com/2079-4991/9/5/801/s1, Figure S1: The G-T-M $\left(\mathrm{M}=\mathrm{Cu}^{2+}, \mathrm{Ni}^{2+}\right.$ and $\left.\mathrm{Co}^{2+}\right)$ coordination nanomaterials prepared by reaction of ammonized GO with corresponding metal nitrates: mononuclear coordination complexes could be formed based on triaminoguanidine ligand, Figure S2: The SEM photos of involved materials, where G-T-Cu, G-T-Co, G-T-Ni, TAG-Co and TAG-Ni are presented.

Author Contributions: Conceptualization, Q.-L.Y. and F.Z.; methodology, T.A. and X.-X.Z.; formal analysis, T.A. and Y.G.; investigation, Q.-L.Y. and S.C.; resources, J.-Y.L.; data curation, D.-Y.T.; writing-original draft preparation, S.C.; writing-review and editing, Q.-L.Y.; project administration, F.Z. and Q.-L.Y.; funding acquisition, Q.-L.Y.

Funding: This research was funded by the National Natural Science Foundation of China, grant number 51776176 and the Scientific Research Ordering Bureau of EDDM China with project number 61407200204.

Conflicts of Interest: The authors declare no conflict of interest. The funders had no role in the design of the study; in the collection, analyses, or interpretation of data; in the writing of the manuscript, or in the decision to publish the results.

\section{References}

1. Kappagantula, K.; Pantoya, M.L.; Hunt, E.M. Impact ignition of aluminum-teflon based energetic materials impregnated with nano-structured carbon additives. J. Appl. Phys. 2012, 112, 024902. [CrossRef]

2. Krause, H.H. New Energetic Materials. In Energetic Materials: Particle Processing and Characterization; Wiley-VCH Verlag GmbH \& Co. KGaA: Weinheim, Germany, 2004; pp. 1-25.

3. Singh, G.; Kapoor, I.P.S.; Mannan, S.M.; Kaur, J. Studies on energetic compounds: Part 8: Thermolysis of Salts of $\mathrm{HNO}_{3}$, and $\mathrm{HClO}_{4}$. J. Hazard. Mater. 2000, 79, 1-18. [CrossRef] 
4. Wang, Y.; Zhu, J.; Yang, X.; Lu, L.; Wang, X. Preparation of NiO nanoparticles and their catalytic activity in the thermal decomposition of ammonium perchlorate. Thermochim. Acta 2005, 437, 106-109.

5. Zhang, W.; Li, P.; Xu, H.; Sun, R.; Qing, P.; Zhang, Y. Thermal decomposition of ammonium perchlorate in the presence of $\mathrm{Al}(\mathrm{OH})_{3} \cdot \mathrm{Cr}(\mathrm{OH})_{3}$ nanoparticles. J. Hazard. Mater. 2014, 268, 446-451. [CrossRef] [PubMed]

6. Xu, J.; Li, D.; Chen, Y.; Tan, L.; Kou, B.; Wan, F.; Jiang, W.; Li, F. Constructing sheet-on-sheet structured graphitic carbon nitride/reduced graphene oxide/layered $\mathrm{MnO}_{2}$ ternary nanocomposite with outstanding catalytic properties on thermal decomposition of ammonium perchlorate. Nanomaterials 2017, 7, 450. [CrossRef] [PubMed]

7. Sergey, V.; Wight, C.A. Kinetics of Thermal Decomposition of Cubic Ammonium Perchlorate. Chem. Mater. 1999, 11, 3386-3393.

8. Liu, T.; Wang, L.; Yang, P.; Hu, B. Preparation of nanometer $\mathrm{CuFe}_{2} \mathrm{O}_{4}$, by auto-combustion and its catalytic activity on the thermal decomposition of ammonium perchlorate. Mater. Lett. 2008, 62, 4056-4058. [CrossRef]

9. Alizadeh-Gheshlaghi, E.; Shaabani, B.; Khodayari, A.; Azizian-Kalandaragh, Y.; Rahimi, R. Investigation of the catalytic activity of nano-sized $\mathrm{CuO}, \mathrm{Co}_{3} \mathrm{O}_{4}$, and $\mathrm{CuCo}_{2} \mathrm{O}_{4}$, powders on thermal decomposition of ammonium perchlorate. Powder Technol. 2012, 217, 330-339. [CrossRef]

10. Chen, L.; Li, L.; Li, G. Synthesis of $\mathrm{CuO}$ nanorods and their catalytic activity in the thermal decomposition of ammonium perchlorate. J. Alloys Compd. 2008, 464, 532-536. [CrossRef]

11. $\mathrm{Xu}, \mathrm{H}$.; Wang, X.; Zhang, L. Selective preparation of nanorods and micro-octahedrons of $\mathrm{Fe}_{2} \mathrm{O}_{3}$, and their catalytic performances for thermal decomposition of ammonium perchlorate. Powder Technol. 2008, 185, 176-180. [CrossRef]

12. Yuan, Y.; Wei, J.; Wang, Y.; Shen, P.; Li, F.; Li, P.; Zhao, F.; Gao, H. Hydrothermal preparation of Fe $\mathrm{O}_{3} /$ graphene nanocomposite and its enhanced catalytic activity on the thermal decomposition of ammonium perchlorate. Appl. Surf. Sci. 2014, 303, 354-359. [CrossRef]

13. Memon, N.K.; Mcbain, A.W.; Son, S.F. Graphene Oxide/Ammonium Perchlorate Composite Material for Use in Solid Propellants. J. Propuls. Power 2016, 32, 682-686. [CrossRef]

14. Gao, X.; Jang, J.; Nagase, S. Hydrazine and Thermal Reduction of Graphene Oxide: Reaction Mechanisms, Product Structures, and Reaction Design. J. Phys. Chem. C 2010, 114, 832-842. [CrossRef]

15. Yan, Q.L.; Gozin, M.; Zhao, F.Q.; Cohen, A.; Pang, S.-P. Highly energetic compositions based on functionalized carbon nanomaterials. Nanoscale 2016, 8, 4799-4851. [CrossRef]

16. He, W.; Guo, J.H.; Cao, C.K.; Liu, X.-K.; Lv, J.-Y.; Chen, S.-Y.; Liu, P.-J.; Yan, Q.-L. Catalytic Reactivity of Graphene Oxide Stabilized Transition Metal Complexes of Triaminoguanidine on Thermolysis of RDX. J. Phys. Chem. C 2018, 122, 14714-14724. [CrossRef]

17. An, T.; He, W.; Chen, S.-W.; Zuo, B.-L.; Qi, X.F.; Zhao, F.Q.; Luo, Y.; Yan, Q.-L. Thermal Behavior and Thermolysis Mechanisms of AP under the Effects of GO-Doped Complexes of Triaminoguanidine. J. Phys. Chem. C 2018, 122, 14714-14724. [CrossRef]

18. Zhang, Y.; Liu, X.; Nie, J.; Yu, L.; Zhong, Y.; Huang, C. Improve the catalytic activity of $\alpha$-Fe ${ }_{2} \mathrm{O}_{3}$, particles in decomposition of ammonium perchlorate by coating amorphous carbon on their surface. J. Solid State Chem. 2011, 184, 387-390. [CrossRef]

19. Jacobs, P.W.M.; Ng, W.L. Thermal decomposition of ammonium perchlorate single crystals. J. Solid State Chem. 1974, 4, 305. [CrossRef]

20. Jacobs, P.W.M.; Pearson, G.S. The thermal decomposition of ammonium perchlorate (i) introduction experimental analysis of gaseous products and thermal decomposition experiments. Combust. Flame 1969, 13, 419. [CrossRef]

21. Chaturvedi, S.; Dave, P.N. A review on the use of nanometals as catalysts for the thermal decomposition of ammonium perchlorate. J. Saudi Chem. Soc. 2013, 17, 135-149. [CrossRef]

22. Mallick, L.; Kumar, S.; Chowdhury, A. Thermal decomposition of ammonium perchlorate-A TGA-FTIR-MS study: Part I. Thermochim. Acta 2015, 610, 57-68. [CrossRef]

23. Sanoop, A.P.; Rajeev, R.; George, B.K. Synthesis and characterization of a novel copper chromite catalyst for the thermal decomposition of ammonium perchlorate. Thermochim. Acta 2015, 606, 34-40. [CrossRef]

24. Wang, X.B.; Li, J.Q.; Luo, Y.J. Preparation and Thermal Decomposition Behaviour of Ammonium Perchlorate/Graphene Aerogel Nanocomposites. Chin. J. Explos. Propellants 2012, 35, 76-80.

25. Wang, X.; Li, J.; Luo, Y.; Huang, M. A Novel Ammonium Perchlorate/Graphene Aerogel Nanostructured Energetic Composite: Preparation and Thermal Decomposition. Sci. Adv. Mater. 2014, 6, 530-537. [CrossRef] 
26. Lan, Y.; Jin, M.; Luo, Y. Preparation and characterization of graphene aerogel/ $\mathrm{Fe}_{2} \mathrm{O}_{3} /$ ammonium perchlorate nanostructured energetic composite. J. Sol-Gel Sci. Technol. 2015, 74, 161-167. [CrossRef]

27. Liu, H.; Jiao, Q.; Zhao, Y.; Li, H.; Sun, C.; Li, X.; Wu, H. Cu/Fe hydrotalcite derived mixed oxides as new catalyst for thermal decomposition of ammonium perchlorate. Mater. Lett. 2010, 64, 1698-1700. [CrossRef]

28. Boldyrev, V.V. Thermal decomposition of ammonium perchlorate. Thermochim. Acta 2006, 443, 1-36. [CrossRef]

29. Rosser, W.A.; Inami, S.H.; Wise, H. Thermal decomposition of ammonium perchlorate. Combust. Flame 1968, 12, 427-435. [CrossRef]

(C) 2019 by the authors. Licensee MDPI, Basel, Switzerland. This article is an open access article distributed under the terms and conditions of the Creative Commons Attribution (CC BY) license (http://creativecommons.org/licenses/by/4.0/). 